Departamento de Zoologia Médica e Parasitologia

Diretor: Prof. Dr. Z. Vaz

\title{
SOBRE A OCURRÊNCIA NO BRASIL DA SARNA PSORÓTICA DOS CAPRINOS E DA SARNA NOTOÉDRICA DO GATO DOMÉSTICO
}

POR

\author{
T. L. Araujo \\ Assistente
}

Com estampas IV - V

\section{SARNA PSOROTICA DOS CAPRINOS}

O fim da presente nota é registrar a presença da sarna auricular em caprinos nascidos e criados em São Paulo.

Em 1938 Cezar Pinto assinalou a ocurrência da sarna enzoótica das capras por Sarcoptes caprae Del e BRUG., 1857 num animal de Manguinhos. Era essa a única espécie de sarna dada como ocorrendo nesses ruminantes, no Brasil, embora o prof. Z. Vaz tivesse observado alguns casos de sarna auricular, em 1934, sem ter, porem, publicado o resultado de suas observações. O material dessas observações, lâminas, peças e fotografias, foi-nos confiado para que o reestudássemos e assinalássemos a presença da otoacariase das cabras no Brasil.

O causador desta sarna é o Psoroptes caprae Rallliet, 1893, acarianos cujas dimensões são: - macho $0,470-0,600 \mathrm{~mm}$. de comprimento; fêmeas ovígeras $0,670-0,740 \mathrm{~mm}$. de comprimento e 0,450 - 0,550 mm. de largura. Esse parasita localiza-se inicialmente na parte interna e no fundo do pavilhão da orelha sem contudo aprofundar-se nos tecidos. De sua atividade resulta uma inflamação com formação de crostas espessas, aderentes e pardacentas (fig. 1).

A sarna, iniciada na parte profunda progride rapidamente para o bordo da orelha, com a sucessão rápida das gerações de psoroptes. Estes são encontrados abundantemente sob as crostas, em todos estádios evolutivos, desde ovo até adultos.

Num dos casos observados as lesões mostravam-se não só na face interna da concha como tambem na externa (fig. 2).

A formação cada vez maior de crostas obstrue o conduto auditivo externo, causando surdez. O prurido intenso, a irritação constante tornam os animais abatidos e fazem com que se alimentem mal ou mesmo recusem de todo os alimentos. O enfraquecimento progres- 
sivo leva os animais à morte, como aconteceu com o pequeno lote de caprinos observados em 1934.

Embora o tratamento desta sarna seja relativamente facil, ela é temivel, porque devido a sua localização, pode passar despercebida no início, mesmo a exame clínico cuidadoso.

\section{SARNA NOTOEDRICA DO GATO}

Em 1935, o prof. Z. Vaz identificou a sarna notoédrica do gato doméstico, em S. Paulo, sarna esta não infrequente, localizada unicamente na cabeça e produzida pelo Notoedres cati (Hering, 1838).

Aproveitamos o ensejo para publicar uma fotografia dum dos casos desta variedade de sarna, caso aliás fatal, que tivemos em mãos, onde se notam lesões extensas particularmente nos pavilhões auriculares (fig. 3). Só se encontra na literatura brasileira referência a este tipo de sarna no livro "Zooparasitas de interesse médico e veterinário», por comunicação verbal de $\mathrm{Z}$. Vaz ao seu autor prof. CEZAR PINTO.

\section{EXPLICAÇÃO DAS FIGURAS}

\section{Estampa IV}

Fig. 1 - Lesões de sarna psorótica em caprino, na face externa do pavilhão da orelha.

Fig. 2 - Idem na face interna.

\section{Estampa V}

Fig. 3-Cabeça de gato doméstico com lesões de sarna notoédrica. 

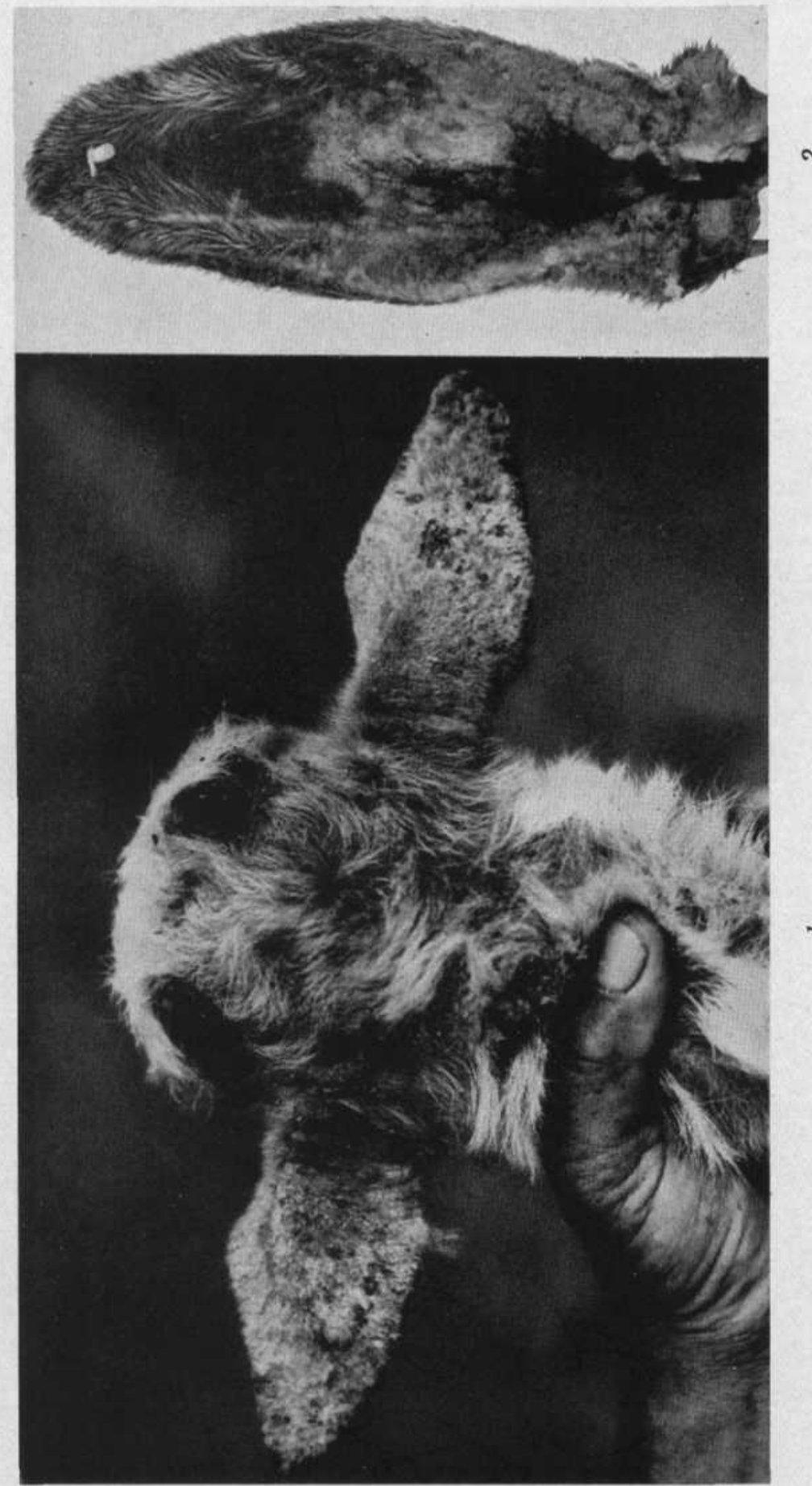


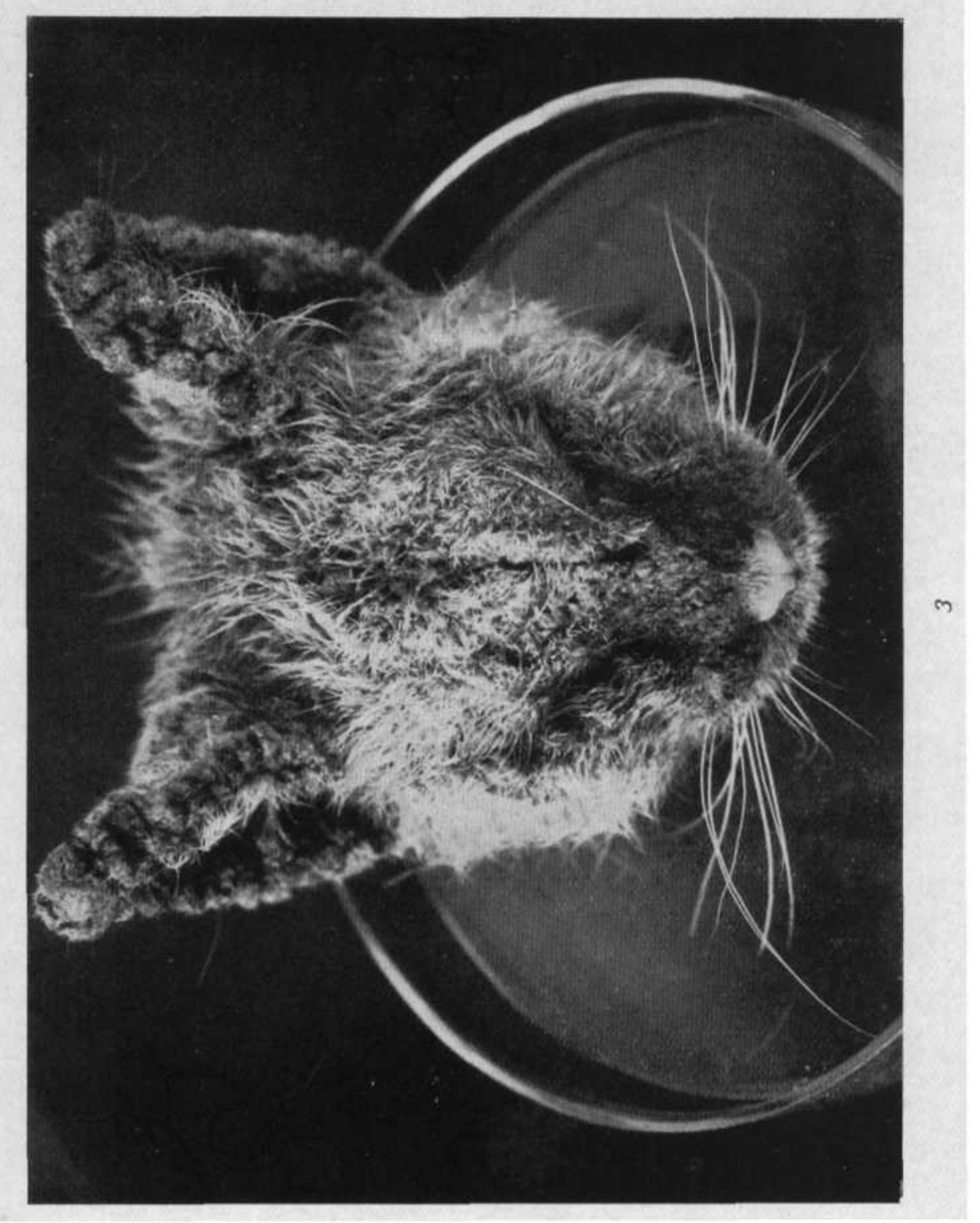

